\title{
Do lugar da busca, à busca de um lugar: a contribuição de Henry Lefebvre
}

Felipe Moura Fernandes ${ }^{1}$

\section{Resumo}

Primeiramente, este trabalho pretende fazer um breve histórico da renovação crítica da geografia brasileira acontecida a partir da década de 70. Em um segundo momento, almejamos apontar e demonstrar algumas das importantes reflexões do filósofo Henry Lefebvre neste processo, contribuindo para a consolidação da idéia de produção social do Espaço. A partir disso, pretendemos desenvolver uma reflexão - também tendo Lefebvre como base - que venha pontuar a importância do Espaço enquanto uma dimensão de análise da sociedade em suas distintas temporalidades. Portanto, não devemos perder a dimensão ensaística deste trabalho.

Palavras-chave: Renovação, Espaço, Henry Lefebvre, Teoria.

\begin{abstract}
First, this paper intends to briefly criticize the renewal of Brazilian geography happened from the '70s. In a second step, point and aim to demonstrate some of the important thoughts of the philosopher Henry Lefebvre in this process, contributing to the consolidation of the idea of social production of space. From this, intend to develop a reflection - and also as a basis Lefebvre - who will score the importance of space as a dimension of analysis of society in its various temporalities. Therefore, we must not lose the size of this essay work.
\end{abstract}

Key words: Renovation, Espace, Henry Lefebvre, Teory.

\section{Primeiros passos: o lugar da busca...}

A Geografia Brasileira passou/passa por um processo de Renovação Crítica e é comum centrarmos este processo de renovação por volta do final da década de 70 e início da década de 80 - tendo como marco o ano de 1978. Este movimento se realiza através de um grande questionamento ideológico e teórico metodológico do paradigma até então estabelecido, sendo este, a Geografia Quantitativa-Teorética que veio se afirmando desde o fim da Segunda Guerra Mundial. Vale destacar que este paradigma estabelecido dizia-se supostamente "revolucionário". Este exclamava que finalmente a 
nossa disciplina obteria o status de ciência² através da base matemática. Neste sentido, é igualmente necessário observar que a Geografia passa por um outro intenso processo de questionamento e crítica desde a década de 50. ${ }^{3}$ Nossa análise, tem como centralidade o primeiro movimento - renovação crítica da geografia. Ainda vale destacar que este pode ser dividido em três vetores, não desconsiderando a relação intensa entre eles: o ideológico, o teórico e o institucional. ${ }^{4}$

O primeiro deles é o movimento de intensa crítica ideológica, onde merece relevância o livro de Yves Lacoste - A Geografia isso serve, em primeiro lugar, para fazer a guerra $^{5}$-, no qual o autor denuncia a existência de uma geografia escolar de atitude e formação extremamente alienante e de uma geografia dos estados maiores de caráter estratégico e político utilizada pelos Estados - Nação. Além disso, Yves Lacoste (2001) também enuncia neste livro uma reflexão teórica trazendo uma reflexão sobre a Espacialidade Diferencial. De igual forma, ainda referente a crítica de caráter mais ideológico, é valido ressaltar as publicações do Boletim Paulista de Geografia (BPG) dos anos de 76 e 77 e também o periódico publicado pelos estudantes "Território Livre". Tal periódico tem o seu número 1 publicado em 1979 e é um importante elemento na divulgação deste momento de crítica/crise. Este primeiro exemplar contava com os seguintes textos e autores: "A Geografia Serve para Desvendar Mascaras Sociais" (ou para repensar a geografia) de Ruy Moreira; "È possível uma 'Geografia Libertadora' ou será necessário uma práxis transformadora? Reflexões Iniciais ( I )", de Ariovaldo Umbelino; e ainda "Em Busca da Ontologia do Espaço", de Antonio Carlos Robert de Moraes, que segundo Armando Corrêa (1983), trata-se de "uma reflexão teórica que aponta a análise política".

O segundo vetor é a crítica de caráter teórico - metodológico, onde destacamos, entre outros já citados, a obra de Milton Santos - nacionalmente - e as reflexões Henry Lefebvre em uma perspectiva mais ampla. Vale ressaltar o livro de Milton Santos, Por Uma Geografia Nova: da crítica da geografia a geografia crítica, onde este inicia um intenso questionamento da Geografia Quantitativa no que diz respeito ao seu estatuto teórico-metodológico. Neste questionamento, a questão principal, a nosso ver, levantada por Milton parece ser o fato de a Geografia de base quantitativa ter negligenciado 0 tempo, o que ele mesmo classifica como sendo o "seu pecado maior". Assim sendo, o autor demonstra que a geografia quantitativa ao negligenciar o tempo subtrai a capacidade de entendimento dos fenômenos de forma processual. Portanto, Milton Santos neste mesmo livro também vai definir o espaço como sendo "uma acumulação desigual de tempos".

"A aplicação corrente das matemáticas à geografia permite trabalhar com estágios sucessivos de evolução espacial, mas é incapaz de dizer alguma coisa sobre como se encontra entre um estágio e outro. Temos, assim, uma reprodução de estágios em sucessão, mas nunca a própria sucessão. Em outras palavras, trabalha-se com resultados, mas os processos são omitidos, o que equivale a dizer que os resultados podem ser objetos não propriamente de interpretação, mas de mistificação". (p.75) 
Um autor igualmente importante no que diz respeito ao estatuto teórico no processo de renovação crítica da Geografia é o filosofo/sociólogo francês Henry Lefebvre, autor de livros como a Sociologia de Marx (ed.fr. 1966), O Direito a Cidade (ed.fr. 1968) e Espaço e Política (ed.fr. 1972) e a Produção Social do Espaço (ed.fr. 1974). Em seu livro Geografias Pós-Modernas, Edward Soja (1993) nos diz que Henry Lefebvre não pode ser enquadrado com um marxista ortodoxo e sua trajetória intelectual acaba por confirmar esse fato. Esse autor demonstra um intenso diálogo com outras bases filosóficas, como 0 existencialismo. Prova disto é a articulação que Lefebvre faz entre o espaço vivido, o espaço percebido e concebido.

Ainda de acordo com Soja (1993) podemos afirmar que:

"Lefebvre aceitou explicitamente a tese de Marx sobre a primazia da vida material na produção do pensamento e da ação conscientes - de que o ser social produzia uma a consciência e não o contrário -, mas se recusou a reduzir o pensamento e a consciência a determinado retoque posterior ou a uma ideação mecânica. Essas idéias brotaram da ligação de Lefebvre com o movimento surrealista francês e de seu existencialismo inicial. Talvez também tenham chegado tão perto de promover um equivalente francês da Escola de Frankfurt contemporânea quanto qualquer outra coisa na França durante o período entre guerras". (p.63)

O terceiro vetor de tal processo de renovação é o institucional que deve ser observado para além das mudanças ocorridas mais adiante no âmbito acadêmico. Neste sentido, vale ressaltar o III Encontro Nacional de Geógrafos (ENG), promovido pela Associação dos Geógrafos Brasileiros (AGB), acontecido em Fortaleza em 1978.

De acordo com Ruy Moreira (2000):

"O 3 ㅌ ENG ensejou o olhar recíproco, o conhecimento dos protagonistas uns dos outros, a conscientização dos descontentamentos que promovem a necessidade das mudanças e a aglutinação das idéias que precipitam a crise da ciência”. (p.29).

Ainda em Armando Correa (1983):

"Na verdade, o encontro teve seu significado maior no âmbito das Comunicações: a mudança de direção da Associação dos Geógrafos Brasileiros, substituição essa que implicou o desaparecimento do caráter oficial (ligado ao IBGE) da entidade e o advento de uma direção jovem e então ainda descomprometida com o poder". (p.77)

Segundo Moreira (2000), é destacado o fato de ter sido durante este Encontro Nacional de Geógrafos que Milton Santos lançou o seu livro "Por uma Geografia Nova" e os estudantes passaram à frente da entidade (AGB) promovendo uma forma de gestão e atuação mais democrática. Deve-se ampliar um pouco este momento/movimento de 
renovação da Geografia Brasileira levando-se em consideração o cenário político nacional. Neste contexto a ditadura militar já demonstrava claros sinais de desgaste e também já havia certa pressão em prol da democratização do país. A partir disso vários intelectuais e artistas que se encontravam no exílio retornaram ao país - processo de anistia - fazendo de sua forma de expressão uma bandeira contra o regime autoritário vigente, como foi o caso de Milton Santos. ${ }^{6}$

\section{A contribuição de Henry Lefebvre: um Marxismo não oficial}

Neste momento pretendemos demonstrar a importância do filósofo Henry Lefebvre em escala internacional e nacional no que diz respeito à consolidação do Espaço como uma categoria importante na análise da sociedade, trazendo também um maior peso de análise, desta, para as ciências sociais como um todo.

Lefebvre não pode e não deve ser enquadrado como um marxista vulgar - de base economicista, atado a relação entre superestrutura e infraestrutura -, na verdade parece que uma das grandes lutas de sua vida foi justamente contra este mesmo marxismo vulgar. De acordo com José de Souza Martins (1996) em seu texto As temporalidades da História na Dialética de Lefebvre ${ }^{7}$ o que unifica a obra de Lefebvre de mais de 30 livros é o retorno à dialética: "Mas um retorno crítico, isto é, retorno a um Marx situado no tempo e na História. O Marx de uma obra inacabada, por isso mesmo cheia de preciosos fios desatados, que era e é preciso retornar". p.13. Neste trecho fica clara a importância da contextualização histórica de Marx e de suas idéias. O Marx apresentado à nós por Henry Lefebvre não é um Marx dogmatizado/fechado e sim um Marx com idéias abertas que ainda permitem muitos avanços e diálogos. Desta maneira, Lefebvre acaba por contrapor - Marxismo de Estado e da mesma forma o Marxismo Oficial que propunha esquemas fechados dogmatizando o seu pensamento dentro da necessidade de se criar estruturas de poder. Também nos vale refletir sobre a produção teórica de Henry Lefebvre e sua militância política no Partido Comunista. Lefebvre ao promover uma ruptura com a leitura Oficial / de Estado de Marx certamente não deve ter agradado aos dirigentes do Partido Comunista. Neste sentido, vale acrescentar que ele ingressou no Partido Comunista na década de 30 tendo bastante destaque, de onde foi expulso após algumas controvérsias depois do XX Congresso do mesmo partido.

"Lefebvre tem presente, e recusa, um Marx falsamente acabado, postiçamente concluído, fetichizado. Na verdade, capturado pelo poder, na necessidade de apresentá-lo como inventor de um sistema - um Marx marxista, adepto e justificador do marxismo oficial, do marxismo de Estado. Mas não marxiano. Isto é, não um Marx de sua própria época, que além de pensar, de produzir idéias, vivia, se envolvia numa prática de transformação da sociedade, ao mesmo tempo envolvido pelos processos de reprodução dessa mesma sociedade". p.13 
E ainda completa dizendo: "Não é um Marx messiânico, embora seja utópico, e profético. Diferentemente do Marxismo oficial, esse Marx mortal porque não tinha poder" p.14.

\section{Sobre o campo teórico-metodológico}

Ainda de acordo com Martins (1996), entendemos que a contribuição de Lefebvre se estende ao campo metodológico. Lefebvre promove um verdadeiro "retorno à dialética" rompendo mais uma vez com o marxismo vulgar. Este autor trabalha com uma ordem de pensamento triádica, assim como Marx - trabalho, terra e capital, ou seja, salário, renda e lucro - ao invés de uma ordem binária como fez o marxismo vulgar. Acreditamos que essa ordem triádica em Lefebvre se traduzirá nas relações entre o espaço vivido, o espaço percebido e o espaço concebido que se estabelecerá através do método progressivo e regressivo. Neste sentido, devemos compreender que para além dos diferentes interesses/conflitos entre as classes e frações de classes sociais, o método traz uma possibilidade de entendimento da realidade que leva em conta as diversas temporalidades que os processos sociais trazem em si. Entendemos que este método está dividido basicamente em três momentos. O primeiro momento onde a descrição e a observação da realidade são fundamentais - este momento está associado às horizontalidades da vida social (continuidades espaço - temporais); no segundo momento o pesquisador deve começar a identificar as diferentes temporalidades que são inerentes ao seu objeto de estudo - este momento está associado às verticalidades da vida social (descontinuidades espaço - temporais); o terceiro momento, deve haver 0 confronto entre o percebido durante a fase de descrição e observação da realidade e o concebido teoricamente - deste terceiro momento há de surgir uma síntese que abrirá novas possibilidades para o vivido. Acabamos por entender que, metodologicamente, devemos partir do vivido. Este vivido nos proporcionara uma determinada apreensão da realidade (percebido) que deve ser confrontado com o conceitual teórico (concebido) e novamente retornado ao vivido. Acreditamos que desta forma Henry Lefebvre reestabelece uma tríade dialética.

"A complexidade horizontal da vida social pode e deve ser reconhecida na descrição do visível. Cabe ao pesquisador reconstituir, a partir de um olhar teoricamente informado, a diversidade das relações sociais, identificando e descrevendo o que vê. Esse é o momento descritivo ${ }^{8}$ do método. Nele, o tempo de cada relação social não está identificado. O pesquisador procede mais como etnógrafo. O segundo é o momento analítico-regressivo. Por meio dele mergulhamos na complexidade vertical da vida social, a da coexistência de relações sociais que tem datas desiguais. Nele a realidade é analisada, decomposta. É quando o pesquisador deve fazer um esforço para datá-la exatamente. Cada relação social tem a sua idade e sua data, cada elemento da cultura material e espiritual também tem sua data. $O$ que no primeiro 
momento parecia simultâneo e contemporâneo é descoberto agora como remanescente de época específica. De modo que no vivido se faz de fato a combinação prática de coisas, relações e concepções que de fato não são contemporâneas. (...) p.21

E ainda continua:

"O terceiro momento do método da dialética de Lefebvre é históricogenético. Nele, deve o pesquisadorprocurer o reencontro do presente", mas elucidado, compreendido e explicado". A volta a superfície fenomênica da realidade social elucida o percebido pelo concebido teoricamente e define as condições e possibilidades do vivido. Nesse momento regressivo-progressivo é possível descobrir que as contradições sociais são históricas e não se reduzem a confrontos de interesses entre diferentes categorias sociais. Ao contrário, na concepção de lefebvriana de contradição, os desencontros são também desencontros de tempos e, portanto de possibilidades." p.21-22

Sobre a relação entre o vivido e o concebido ainda contribui Odete Seabra (1996) em seu texto a Insurreição do Uso:

"É preciso refletir com base no vivido, mas sem recusar o concebido e exaltar a espontaneidade do vivido, pois que ele também se determina; tanto que, analisando- o, é possível ver como a parte cega da história diminui e como no caráter confuso do vivido está sua riqueza quanto a sua pobreza. Enfim, o discurso sobre o cotidiano tem de tornar explícito o que está implícito" p.80

Esquema explicativo da relação: vivido, percebido e vivido / exercício teórico e metodológico lefebvriano.

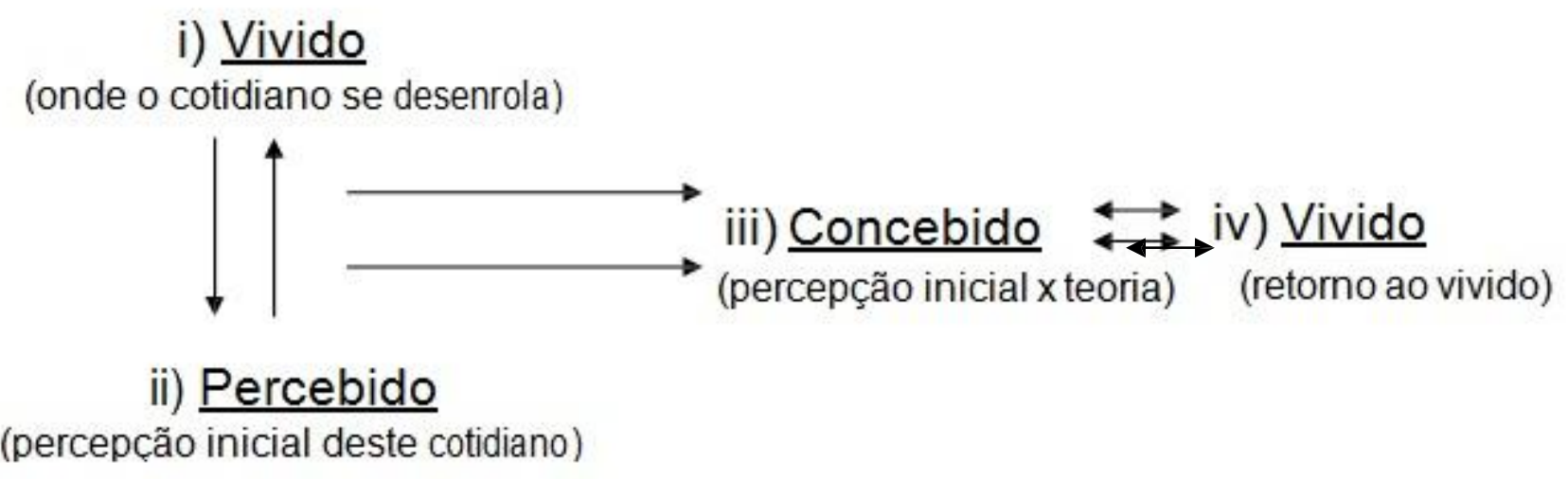




\section{Aproximações: Henry Lefebvre e Milton Santos}

São várias as intercessões possíveis entre as reflexões de Henry Lefebvre e do geógrafo brasileiro Milton Santos. Dentre elas, destacamos, a reflexão sobre a categoria Marxiana Formação Econômica e Social (FES) e a definição de rugosidades utilizada por Milton Santos, acreditamos que essas reflexões possuem um caráter complementar.

Ainda a partir de Martins (1996) podemos observar que Henry Lefebvre faz uso da categoria FES para demonstrar a importância de um olhar que tente abarcar a uma determinada totalidade dentro de uma perspectiva global. Esta categoria também deve pautar a relação do homem com a natureza em temporalidades diferenciadas associada à idéia de Modo de Produção. O Modo de Produção Capitalista, por exemplo, vai pautar a relação homem - natureza de maneira diferenciada de outros momentos históricos. Assim sendo, a partir de uma perspectiva que leva em consideração a idéia de evolução histórica - sem fazer juízo de valor - podemos fazer algumas considerações: o homem ao tomar "consciência de si" e conseqüentemente do mundo que o cerca vai intensificar cada vez mais a sua relação/transformação da natureza, transformando a mesma e a si mesmo. Neste momento já nós é permitido falar em segunda natureza - assim como em Marx de acordo com Martins. A segunda natureza (naturans naturata) ${ }^{9}$ seria justamente a "natureza" que seria resultante da relação do homem com o que poderíamos chamar de primeira natureza (natura naturans).

Desta maneira Martins (1996):

"No retorno a Marx, o retorno ao núcleo explicativo do processo histórico: a relação homem x natureza; o homem que, na atividade por meio da qual atua sobre a natureza para saciar-se, para atender suas necessidades, modifica a natureza e modifica suas próprias condições de vida, modificando ao mesmo tempo sua relação com a natureza. Deixando, portanto, de ser repetitivo e reativo. Desafiado a imaginar e criar, modificando suas condições de vida e modificando-se ao mesmo tempo, constituindo-se como humano, humanizando-se. Lefebvre descobriu que essa tese de $A$ ideologia Alemã ganha consistência numa noção mal formulada na obra de Marx: a de formação econômico-social (...)".

"O reencontro da noção de formação econômico-social por Lefebvre tem amplas implicações, pois é a noção que 'tem uma significação profunda e dupla: metodológica e teórica”". p.15-16

Milton Santos em seu livro Por uma Geografia Nova também faz uso da formulação Marxiana FES para também relaciona - lá a uma perspectiva de totalidade e diferentes temporalidades inerentes a essa mesma totalidade. Essas diferentes temporalidades dentro de uma mesma totalidade parecem ficar claras na utilização da sua formulação de "rugosidades espaciais". As rugosidades, em nosso entendimento, são justamente a presence dessas diferentes temporalidades materialmente presentes no espaço geográfico. Os diferentes estilos arquitetônicos - colonial, eclético, moderno e pós- 
moderno - encontrados em uma metrópole como o Rio de Janeiro, por exemplo, dão conta de registrar diferentes temporalidades materialmente presentes naquele espaço geográfico. O edifício Paço Imperial é o registro material de um tempo pretérito que não existe mais. No entanto ele se faz ali presente, não cumprindo as mesmas funções, mas mantendo uma determinada forma pretérita. A contemporaneidade está imersa em processos diferenciados daquele tempo histórico (colonial) por estar inserido em uma estrutura diferenciada. ${ }^{10}$

\section{Sobre a relação entre Espaço e Política}

Como já explicitado anteriormente Lefebvre em 1972 - data da primeira edição francesa - lançara um livro chamado Espaço e Política. Este livro será uma espécie de continuação as reflexões desenvolvidas em O Direito a Cidade de 1968 - data também da primeira edição francesa. Ao nos debruçarmos sobre os capítulos iniciais de Espaço e Política acabamos por confirmar a perspectiva dialética, não dicotômica presente nas suas reflexões. De acordo Lefebvre (1976) em Espaço e Política: "A fragmentação se traduz em uma analise errônea, não crítica (...)" p.9.

Neste sentido, algo que aparece de forma ímpar neste texto é a importância que este autor atribui ao cotidiano. Sendo assim, parece-nos que esse fato está associado ao destaque dado ao "vivido" em seu exercício de caráter mais teórico e metodológico que tentamos expor anteriormente.

Desta mesma forma, este discorre sobre a não neutralidade do espaço e da ação dos agentes sociais sobre esse mesmo espaço realçando o seu aspecto político. Ressalta que possuímos uma visão opaca da realidade, visão essa que mascara a realidade ao invés de proporcionar uma compreensão real: "magia ideológica". Entendemos que um dos fatores que acabam por proporcionar essa visão opaca da realidade é a negligência do espaço na análise da sociedade.

O autor ressalta que a ação da burocracia estatal acaba por promover uma organização do espaço de acordo com as exigências do sistema, do modo de produção capitalista. A ação do Estado acaba por reforçar uma apreensão fragmentada da realidade, conseqüentemente do espaço. Essa fragmentação do espaço está atrelada à transformação do espaço em mercadoria. Tal fragmentação está pautada em projetos que são concebidos e visualizados apenas no papel, sem uma preocupação maior com a totalidade espacial a qual este envolve. Um pouco mais adiante, em seu texto, Lefebvre faz uma belíssima crítica aos arquitetos. Dizendo que estes fazem seus projetos, seus desenhos, em "folhas em branco" e tendem a confundir essa folha em branco, possivelmente neutra, com realidade social na qual esse projeto será executado. Os arquitetos em seu ofício acabam por confundir "projeção e projeto".

Neste sentido, Henry Lefebvre nos contempla:

"O arquiteto produtor do espaço (porém, nunca sozinho) opera sobre um 
espaço específico. E como primeira providência, tem diante dele, sobre seus olhos, sua mesa de desenho, sua folha em branco. $O$ encerrado não exerce efeitos muito diferentes. Essa folha de papel de desenho, quem a vai considerar um simples espelho e por sujeição, como um fiel espelho? Quando, de fato, todo espelho é enganoso e, ademais, essa folha de papel em branco é algo mais que um espelho. $O$ arquiteto a utiliza para traçar seus planos, vocábulo que se deve contemplar em toda sua força: superfície plana, sobre a qual um lápis mais ou menos ágil e habilidoso traça linhas que o autor considera como a representação das coisas, do mundo sensível, quando, de fato, a superfície impõe um decifrado - recifrado do real. Contrariamente ao que facilmente crê, o arquiteto não pode localizar seu pensando e suas percepções sobre a mesa de desenho e visualizar as coisas (necessidades, funções, objetos), projetando-as. Confunde projeção e projeto submergido em uma idéia confusa que ele crê real e, inclusive, rigorosamente concebida, dado que os procedimentos cifrado e decifrado mediante o desenho são usuais e tradicionais; que, a partir desse momento, escapam a sua influência. A folha, ao alcance da mão do desenhista, sobre seus olhos fica em branco, tão branca como plana. A considera como neutra, crê que esse espaço neutro, que recebe passivamente os traços de seu lápis corresponde ao espaço neutro de fora, que recebe as coisas, ponto por ponto, lugar por lugar. Quanto ao plano, não permanece inocentemente sobre a folha de papel. (....). p.12.

Tendo como elemento suleador a reflexão de Henry Lefebvre, vale ressaltar a importância da discussão teórica - presente neste esforço de síntese - para o nosso amadurecimento no entendimento da realidade que nos cerca, dentro da relação: teoria e a prática. Dessa forma, vale parafrasear o historiador espanhol Júlio Aróstegui, cuja opinião nós é comum, ao dizer que é impossível haver evolução na ciência sem discussão teórica, sem uma discussão sobre a sua "natureza".

Assim, este breve ensaio surge como uma possibilidade de diálogo, não estando, de forma alguma fechado ou tendo grandes preocupações sistemáticas. Acreditamos que este trabalho, está situado historicamente e pretende contribuir para o contínuo processo de renovação crítica de nossa disciplina, iniciado na década de 70 e nunca terminado.

\section{Notas}

1- Professor da Faculdade de Formação de Professores da Universidade do Estado do Rio de Janeiro e Professor da Rede Estadual do Rio de Janeiro

2- Ver Ligia Oliveira (1973) em seu texto "A Renovação da Geografia" onde a autora coloca "considerações iniciais" que devem orientar a "natureza e perspectiva da renovação na geografia", a dita Revolução Quantitativa: "A natureza da renovação na 
Geografia pode ser abordada sob tríplice aspecto: a integração no contexto científico, a utilização da linguagem matemática e o desenvolvimento de teorias geográficas. Dentro desta colocação, tanto uma teorização, quanto uma quantificação, apresentam-se como aberturas de perspectivas para a ciência geográfica".

3- De acordo com Armando Correa (1983). “(...) na atualidade desenvolveu-se a crítica as posições tradicionais, iniciando-se tal processo na década de 50". Na mesma publicação, Armando comenta Roberto Lobato em seu texto "da nova geografia a geografia nova" publicado na coletânea Geografia e Realidade: "a Geografia passou por uma 'revolução' na década de 50, sendo até então caracterizada pela abordagem regional, de um lado, e, de outro, pela abordagem ecológica".

4- Ver dissertação de Mestrado: SACARIM, Paulo César. Coetâneos da Crítica: uma contribuição ao estudo da renovação da geografia brasileira. Dissertação de Mestrado (Mestrado em Geografia) - Departamento de Geografia, Universidade de São Paulo. São Paulo, 2001.

5- LACOSTE, Yves. A geografia isso serve, em primeiro lugar, para fazer a guerra. São Paulo. Ed. Papirus, 2001.

6- De acordo com Milton Santos em entrevista encontrada na coletânea Testemunha Intelectual p. 16: "No caso da Geografia, o que me ajudou é que havia a AGB, Associação dos Geógrafos Brasileiros, que por sorte ficou pobre e, por conseguinte, sua burocracia é frágil. No fim dos anos 70 , ela foi abandonada pelos grandes patrões, então entraram jovens, entre os quais uma parte não tinha emprego. No meu caso foi uma alavanca formidável: era uma instituição, mas não o suficiente institucional, não burocratizada". No texto inacabado após a entrevista Milton Santos continua: "É a partir dos anos 70, e, sobretudo após 1978, que o debate se desloca e enriquece. Antes a discussão, pouco explicitada, entre new geographers e "tradicionalistas". Já agora é entre uma geografia apontada como falseadora da verdade e uma geografia crítica desejosa de restabelecê-la e igualmente critica a geografia tradicional. Vejam o meu Por Uma Geografia Nova e o livro organizado por Ruy Moreira, Geografia, teoria e crítica".

7- Parte do livro organizado pelo mesmo José de Souza Martins (1996): "Henry Lefebvre e o retorno a Dialética".

\section{8- Grifos nosso}

9- A relação entre natura naturans como primeira natureza e naturans naturata como segunda natureza e explicitada por Ruy Moreira (2000) em seu texto, Assim se Passaram Dez Anos (A Renovação da Geografia no Brasil no Período 1978 - 1988) In: Geographia, ano 2, no 3 Revista do Programa de pós-graduação em geografia do departamento da Universidade Federal Fluminense (UFF). 
10- Poderíamos estender essa breve relação entre as reflexões de Henry Lefebvre e Milton Santos um pouco mais, intensificando a relação entre a categoria Marxiana FES e o exercício teórico-metodológico de Milton Santos presente em seu livro Espaço e Método (1985) a partir das categorias: forma, processo, função e estrutura. No entanto, devido à exigüidade de tempo e o caráter ensaístico do trabalho não podemos estender muito. Sendo de nossa pretensão poder voltar a e aprofundar essas relações futuramente.

\section{Bibliografia}

LACOSTE, Yves. A geografia isso serve, em primeiro lugar, para fazer a guerra. São Paulo. Ed. Papirus, 2001.

LEFEBVRE, Henry. El Espacio. In: LEFEBVRE, Henry. Espacio e Política - el dercho a la ciudad II. Barcelona. Ed. Península, 1976.

MARTINS, José de Souza. As temporalidades da história na dialética de Lefebvre. In: MARTINS, José de Souza (Org.), Henry Lefebvre e o retorno à dialética. São Paulo, Ed. Hucitec, 1996.

MOREIRA, Ruy. Assim se passaram dês anos - a renovação da Geografia Brasileira no período 1978-1988. Geographia, Revista do Programa de Pós-Gradução em Geografia da UFF n? ? junho, 2000.

OLIVEIRA, Lívia. A Renovação da Geografia. In: Simpósio Renovação da Geografia AGB/XXV Reunião anual da SBPC. Rio de Janeiro. AGB-São Paulo, 1973.

SANTOS, Milton. Espaço e Método. São Paulo. Ed. Nobel, 1985.

. A Natureza da Espaço. São Paulo. Ed. Edusp, 2002.

Por Uma Geografia Nova. São Paulo. Ed. Edusp, 2002.

. Testemunho Intelectual. São Paulo. Ed. Unesp, 2002.

SCARIM, Paulo César. Coetâneos da Crítica: uma contribuição ao estudo da renovação da geografia brasileira. Dissertação de Mestrado (Mestrado em Geografia) Departamento de Geografia, Universidade de São Paulo. São Paulo, 2001.

SEABRA, Odete C. de Lima. A insurreição do uso. In: MARTINS, José de Souza (Org.), Henry Lefebvre e o retorno à dialética. São Paulo, Ed. Hucitec, 1996.

SILVA, Armando Corrêa da. A Renovação Geográfica no Brasil - 1976-1983: as 


\section{REVISTA TAMOIOS}

Geografias Radical e Critica na Perspectiva Teórica: In: Boletim Paulista de Geografia, no 60. São Paulo: AGB-São Paulo, 1983.

SOJA, Edward W. Geografias Pós-Modernas: a reafirmação do espaço na teoria social crítica. Rio de Janeiro. Ed. Jorge Zahar, 1993. 